\title{
Lesões Palpebrais no Lúpus Eritematoso
}

\section{Lid Lesions in Lupus Erythematosus}

\author{
Ana Paula Beckhauser ${ }^{(1)}$, Liz Wallim ${ }^{(1)}$, Leonardo Schmidt ${ }^{(1)}$, Marilia Barreto Silva $^{(2)}$, Thelma L. Skare ${ }^{(2)}$
}

\section{RESUMO}

O envolvimento cutâneo do lúpus eritematoso, quando aparece de maneira isolada em pálpebra, pode ser de difícil diagnóstico. Diagnósticos errôneos são comuns, principalmente o de blefarite resistente a tratamento. Todavia o diagnóstico precoce é importante no sentido de evitar a cicatrização e possíveis seqüelas nas delicadas estruturas locais. Descrevem-se três casos de lesões palpebrais em pacientes com lúpus eritematoso, e, em cada uma das situações, essa lesão teve um significado clínico diferente. Nas duas primeiras pacientes, firmou-se o diagnóstico de lesão discóide pela biópsia. Na terceira paciente encontrou-se um carcinoma basocelular.

Palavras-chave: lúpus eritematoso, doenças palpebrais, prognóstico.

\section{INTRODUÇÃO}

O envolvimento cutâneo no lúpus eritematoso é buscado cuidadosamente pelo médico para ajudar tanto no diagnóstico da doença quanto no prognóstico desta. O espectro dessa forma de envolvimento é rico, variando de lesões bastante específicas a outras que, embora inespecíficas, podem trazer informações valiosas sobre a gravidade ou a atividade da enfermidade ${ }^{(1,2)}$. Outro grupo delas pode ser causado pelas complicações da doença ou pelo uso de medicamentos ${ }^{(1,2)}$.

A pálpebra é um local onde podem aparecer lesões do lúpus, embora seu achado seja pouco comum ${ }^{(3)}$. Neste texto são descritos três pacientes com lesões palpebrais e lúpus, tendo cada uma delas um significado totalmente diferente para a condução do caso em questão.

\section{DESCRIÇÃO DOS CASOS}

\section{PACIENTES COM LESÕES PALPEBRAIS}

PELO LÚPUS CUTÂNEO

\section{PACIENTE 1}

Paciente de 27 anos, sexo feminino, procura o oftalmologista por causa de lesões erosivas em ambas as pálpebras de início há três meses e evolução gradativa. Negava a existência

\begin{abstract}
The cutaneous involvement of lupus erythematosus is difficult to diagnose when it appears isolated in the eyelid. Misdiagnosis is common, confusions arising mainly with chronic resistant blepharitis. Yet the early diagnosis is important to avoid scarring and damage to the delicate local structures. We present three patients with lupus and eyelid cutaneous lesions, each of them with a different clinical significance. In the first two patients it was possible to diagnose discoid lesion through skin biopsy. In the third, a basocelular carcinoma was found.
\end{abstract}

Keywords: lupus erithematosus, eyelid diseases, prognosis.

de qualquer outra lesão cutânea, artralgias ou artrite, fotossensibilidade, Raynaud, úlceras orais e nasais. Não existia história pregressa digna de nota. Investigação feita anteriormente mostrava um FAN positivo no título de 1:80 (padrão pontilhado), hemograma, parcial de urina e complementos normais. A lesão cutânea (Figuras l e 2) foi submetida à biópsia, sendo o material enviado para análise histológica. $\mathrm{O}$ resultado demonstrou espessamento da membrana basal e hiperqueratose; infiltração linfocitária difusa em derme, maior ao redor de vasos. Imunofluorescência com depósitos de IgA, IgG, IgM e C3 em membrana basal, de aspecto contínuo e granulomatoso.

Com diagnóstico de lúpus discóide, a paciente foi tratada com corticóide tópico e houve melhora das lesões.

\section{PACIENTE 2}

Paciente do sexo feminino, de 42 anos, com diagnóstico de lúpus discóide há 18 meses, estava em tratamento pelo serviço de dermatologia do Hospital Evangélico de Curitiba, usando cloroquina e protetor solar. Investigação anterior mostrava que FAN que era negativo. Comparece à consulta de rotina contando que apareceram lesões palpebrais erosivas bilaterais no canto externo das pálpebras há dois meses, com sensação de queimação no local, tendo procurado oftalmologista que prescreveu colírios (sic) sem melhora.

Recebido em 12/2/2008. Aprovado, após revisão, em 23/4/2008. Declaramos a inexistência de conflitos de interesse.

1. Médicos-residentes do Serviço de Reumatologia do Hospital Universitário Evangélico de Curitiba (HUEC).

2. Médicas do Serviço de Reumatologia do HUEC.

Endereço para correspondência: Thelma L. Skare, Rua João Alencar Guimarães, 7.967, 80310-420, Curitiba, PR, Brasil, e-mail: tskare@onda.com.br. 

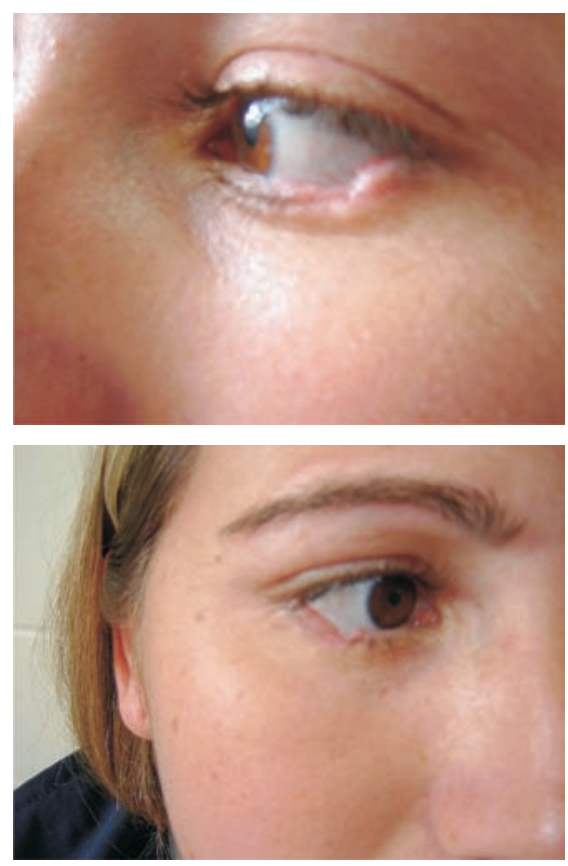

Figuras 1 e 2 - Lesões palpebrais da paciente do caso número 1.

Ao exame físico viam-se lesões erosivas no canto externo de ambos os bordos palpebrais inferiores com perda local dos cílios (Figura 3 e 4). Foi submetida à biópsia que demonstrou acantose irregular e ceratose lamelar discreta, focos de alteração vacuolar na membrana basal; infiltrado linfocitário denso em volta de vasos. À coloração com PAS, a membrana basal se mostrou espessada. À imunofluorescência, detectaram-se depósitos granulosos de IgA, IgG, IgM e C3.

Com diagnóstico de envolvimento discóide em pálpebras, essa paciente foi mantida no uso do antimalárico e recebeu um curso de corticóides orais $(20 \mathrm{mg} / \mathrm{dia})$ por 15 dias, o que foi sendo gradativamente diminuído à medida que a paciente apresentava melhora.

\section{PACIENTE COM LES E LESÃO PALPEBRAL POR DOENÇA MALIGNA}

\section{PACIENTE 3}

Mulher, 26 anos, branca, com diagnóstico de lúpus eritematoso sistêmico (LES) há dez anos, comparece à consulta para exames de rotina. O diagnóstico de LES foi feito com base na presença de glomerulonefrite classe 3 da Organização Mundial da Saúde (OMS), rash em borboleta, artrite, FAN positivo e consumo de C3 e C4. Além disso, tinha tireoidite de Hashimoto e vitiligo com máculas em mãos. Necessitou tratamento com corticóides, antimalári-
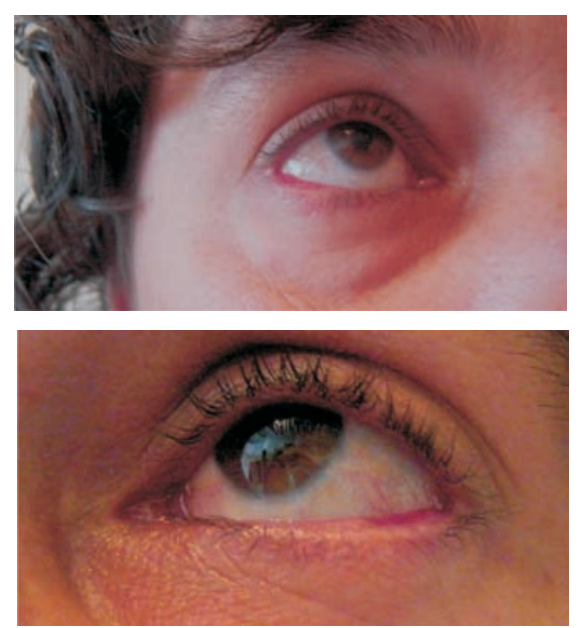

Figuras 3 e 4 - Lesões palpebrais da paciente do caso número 2.

cos e ciclofosfamida (seis meses), a qual foi posteriormente substituida por azatioprina com controle da doença. Cerca de um ano antes da consulta atual teve novo surto de glomerulonefrite, necessitando de retratamento com ciclofosfamida (seis meses), seguida de azatioprina.

Ao comparecer para consulta de rotina observou-se lesão erosiva em pálpebra inferior esquerda (unilateral) com perda local de cílios (Figuras 5 e 6). Biópsia da lesão mostrou tratar-se de carcinoma basocelular, sendo encaminhada para ressecção, a qual foi feita com sucesso. Exame histológico do material ressecado confirmou o diagnóstico anterior.
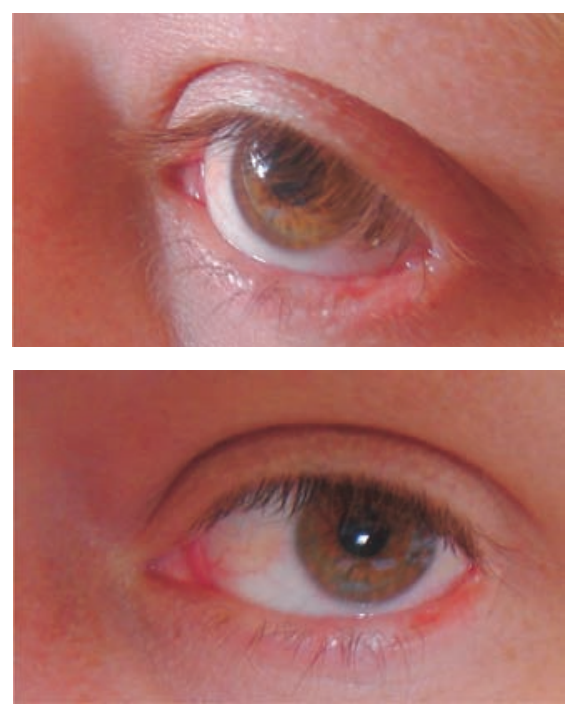

Figuras 5 e 6 - Imagens da lesão palpebral esquerda da paciente do caso número 3. 


\section{DISCUSSÃO}

As lesões de pele aparecem em torno de $70 \%$ dos pacientes com LES, sendo seu achado extremamente útil para o diagnóstico dessa entidade ${ }^{(2)}$. Em cerca de um quarto dos pacientes, a manifestação de pele está presente ao diagnóstico, sendo esta a segunda mais freqüente, preterida apenas pelas manifestações articulares ${ }^{(4)}$. Sua importância fica bastante explícita ao se observar que quatro dos 11 critérios de classificação para essa doença propostas pelo Colégio Americano de Reumatologia são dermatológicos: fotossensibilidade, eritema malar, úlceras orais e lesões discóides ${ }^{(1)}$. Em certos casos, a lesão cutânea oferece também ajuda no prognóstico e na previsão de envolvimento de determinados órgãos internos ${ }^{(4-6)}$.

As lesões palpebrais em pacientes com LES e discóide não são comuns e foram descritas inicialmente em 1932, sendo diagnosticadas, em geral, pelo oftalmologista ${ }^{(3)}$. De acordo com Mseddi et al. ${ }^{(7)}$, ele prefere o bordo inferior e externo da pálpebra, como o observado nos dois primeiros casos. Quando a lesão palpebral se apresenta de maneira isolada, como na primeira paciente descrita, pode ser de difícil diagnóstico, sendo possível, pelo estudo anatomopatológico com imunofluorescência do material de biópsia. Neste contexto, não é raro que seja confundida, no momento inicial, com blefaroconjuntivite crônica. Acharya $e t$ al ${ }^{(8)}$ sugerem que pacientes com blefaroconjuntivite crônica que não respondem ao tratamento usual sejam submetidos à biópsia para excluir a possibilidade de lesão de lúpus cutâneo. Outras doenças que devem entrar no diagnóstico diferencial são as dermatites de contato, rosácea, tínea facial, líquen plano, penfigóide cicatricial e erupção polimorfa à luz ${ }^{(2)}$.

Na segunda paciente, o envolvimento palpebral foi apenas uma lesão adicional de um quadro mais completo de lúpus cutâneo sem maiores significados, sendo tratada no contexto geral da doença. Não teve mais repercussões para a paciente, embora seja fato sabido que existem algumas descrições da lesão cutânea palpebral em pacientes com lúpus cutâneo que evoluíram para $\operatorname{LES}^{(3,9)}$. Paroli et al. . $^{(10)}$ descrevem o caso de um paciente com a forma sistêmica da doença, em remissão por 15 anos, em que as lesões das pálpebras associadas ao envolvimento da coróide foram os únicos sinais de recidiva. Naturalmente, as complicações locais também são possíveis, uma vez que o lúpus discóide leva à formação de cicatrizes que podem causar ectrópio e/ou entrópio, simbléfaro, além de possuírem efeito es- tético indesejável ${ }^{(8)}$. Casos mais raros de lesões discóides hipertróficas na conjuntiva têm sido descritos ${ }^{(2)}$.

O tratamento das lesões palpebrais segue os moldes do tratamento do lúpus discóide em geral, sendo recomendados a fotoproteção com óculos escuros e os filtros solares, uso tópico ou sistêmico de corticóides, antimaláricos e imunossupressores, como azatioprina, dapsona e metotrexato ${ }^{(2,11)}$.

O maior aprendizado, entretanto, pode aparecer da análise do caso da terceira paciente. Sendo ela uma paciente jovem, com a forma sistêmica da doença, até mesmo com envolvimento renal, acreditou-se inicialmente que a análise anatomopatológica seria compatível com lesão discóide. Surpreendentemente, observou-se uma lesão maligna. A grande diferença observada clinicamente entre esse caso e os demais reside no fato de que, neste último, a lesão palpebral era unilateral.

Carcinoma espinocelular tem sido descrito sobre lesões discóides de longa duração ${ }^{(1)}$, o que não era $o$ caso dessa paciente, sem lesões prévias no local. Além disso, a anatomia patológica demonstrou tratar-se de um basocelular. Outro aspecto marcante foi a juventude da paciente descrita, uma vez que a prevalência do carcinoma basocelular tende a aumentar com a idade, principalmente acima de $50 \operatorname{anos}^{(6)}$.

Não se pode esquecer que o LES tem sido associado com maior aumento de malignidades, que já foram devidamente documentadas ${ }^{(11-14)}$. Todavia as mais $\mathrm{co}^{-}$ mumente descritas são as de mama, pulmão e órgãos ginecológicos ${ }^{(12)}$. O uso prévio de imunossupressores é outro fator potencialmente associado ao aparecimento de doenças malignas. Tanto a azatioprina quanto a ciclofosfamida estão ligadas a essa associação. Segundo Decker et al. ${ }^{(15)}$, carcinomas de pele aparecem quatro vezes mais comumente em usuários de azatioprina e nove vezes mais comumente em usuários de ciclofosfamida.

Analisando-se os três casos apresentados, pode-se observar que a lesão palpebral no primeiro caso permitiu o diagnóstico do lúpus; no segundo, comportou-se apenas como um componente do espectro da doença e no terceiro mostrou uma possível complicação desta ou de seu tratamento, que poderia ter tido conseqüências mais graves, principalmente em razão da localização da lesão. Assim sendo, o médico que trata de pacientes com lúpus deve manter o olho nos olhos dos pacientes. 


\section{REFERÊNCIAS}

1. Monouni D, Nousari CH: Systemic Lupus erythematosus: the skin. In Lahita RC (ed). Systemic lupus erythematosus. San Diego: Elsevier, 2004. p. 855-76.

2. Patel $P$, Werth V: Cutaneous lupus erythematosus: a review. Dermatol Clin 20: 373-85, 2002.

3. Pandhi D, Singal A, Rohtagi J: Eyelid involvement in disseminated chronic cutaneous lupus erythematosus. Indian J Dermatol Venereol Leprol 72(5): 370-2, 2006.

4. Zecevié RD, Vojvodiè D, Ristié B, Pavlovié MD, Stefanovié D, Karadaglié D: Skin lesions: an indicator of disease activity in systemic lupus erythematosus? Lupus 10: 364-7, 2001.

5. Enríquez R, Sirvent AE, Amorós F, Pérez M, Matarredona J, Reyes A: Crescentic membranoproliferative glomerulonephritis and hypocomplementemic urticarial vasculitis. J Nephrol 18: 318-22, 2005.

6. Sontheimer RD: Subacute cutaneous lupus erythematosus: 25 year evolution of a prototypic subset (subphenotype) of systemic lupus defined by characteristic cutaneous, pathological, immunological, and genetic findings. Autoimmun Rev 4: 253-63, 2005.

7. Mseddi M, Marrakchi S, Meziou TJ, et al.: Lupus érythémateaux discoide et paupiére. Une serie de 9 patients. J Fr Ophtalmol 30: 247-9, 2007.
8. Acharya N, Pineda R, Uy HS, Foster S: Discoid lupus erythematosus masquerading as chronic blepharoconjuctivitis. Ophtalmology 112: e-19-23, 2005.

9. Donzis PB, Insler MS, Buntin DM, Gately LE: Discoid lupus erythematosus involving the eyelids. Am J Ophtalmol 98: 32-6, 1984.

10. Paroli MP, Riso D, Pinca M, Pivette-Pezzi P: Chorioretinopathy and discoid plaques like lesions of the eyelids as useful indicators of systemic lupus erythematosus progression. Lupus 10: 571-5, 2001.

11. Christenson LJ, Borrowman TA, Vachon CM, et al.: Incidence of basal cell and squamous cell carcinomas in a population younger than 40 years. JAMA 294: 681-90, 2005.

12. Ramsey-Goldman R, Mattai SA, Schilling E, et al.: Increased risk of malignancy in pacients with systemic lupus erythematosus. J Invest Med 46: 217-22, 1998.

13. Sweeney DM, Manzi S, Janosky J, et al.: Risk of malignancy in women with systemic lupus erythematosus. J Rheumatol 22: 1478$82,1995$.

14. Abu-Shakra M, Gladman DD, Urowitz MB: Malignancy in Systemic lupus erythematosus. Arthritis Rheum 39: 1050-4, 1996.

15. Decker JL: Azathioprine and ciclofosfamide as slow acting drugs for rheumatoid arthritis. Am J Med 75: 74-8, 1978. 